\title{
TOTAL PERIPHERAL RESISTANCE AND DIASTOLIC BLOOD FLOW
}

\author{
P.J. TomLIN, F.F.A.R.C.s., ${ }^{\circ}$ AND F.A. Duck, M.sC.
}

The Estimation of the total peripheral resistance is tedious and difficult to apply to an intact subject, and in clinical practice one has to rely on the clinical evaluation of the patient's appearance. During observations on aortic blood flow in dogs using a transoesophageal ultrasonic flowmeter, ${ }^{1}$ it was noticed that during diastole there was a forward flow of blood, and that the extent of this appeared to vary with the physiological status of the animal. It was decided to study this further, over a wide spread of total peripheral resistance in the circulation, to see if there was any relationship between this and the proportion of the stroke volume flowing down the descending aorta during diastole. If there was such a relationship that could be observed by a relatively non-invasive technique this could have significant clinical advantages.

\section{METHODS}

Anaesthetized and mechanically ventilated dogs were studied. Anaesthesia was induced by pentobarbitone and the lungs were ventilated with a constant volume ventilator.

\section{Techniques of Measurement}

An electromagnetic flowmeter was placed around the ascending aorta, and another around the descending aorta about four centimeters above the diaphragm. Calibration of the electromagnetic flowmeters was made in vitro. A short wide bore rigid cannula was passed through the left ventricular wall into the left ventricle and connected directly to an electromanometer (Statham P37) for the instantaneous measurement of left ventricular pressure. Its instantaneous derivative was then obtained by electronic differentiation of the pressure signal and recorded on another channel of the recorder. The pressure transducers were calibrated using standard mercury manometers, and calibration of the differentiator output was done by comparing the tangent of the pressure waves, observed during high

From the Divisions of Radiology and Anaesthetics, Faculty of Medicine, Memorial University, St. Johns, Newfoundland.

-Present address: University Department of Anaesthetics, Queen Elizabeth Hospital, Birmingham B15.

This study was supported in part by the Canadian Heart Foundation to whom the authors express their thanks.

P.J. Tomlin, F.F.A.R.C.S., Visiting Professor in Anaesthetics Memorial University, St. Johns, Newfoundland.

F.A. Duck, M.Sc. Research Fellow., Department of Radiology Memorial University, St. Johns, Newfoundland. 
speed recordings, with the output of the differentiator channel. The 95 per cent amplitude frequency response was obtained by polaroid photography of the oscilloscopic tracing resulting when a pressurized water-filled balloon attached to the cannula used for the intraventricular pressure recording, was burst. This amplitude frequency response was better than twenty times the heart rate, thus conforming to the critical criteria for measurement of $\mathrm{dp} / \mathrm{dt}$ laid down by Gersch et al. ${ }^{2}$ Intra-arterial pressure was measured with a saline filled catheter and another P37 pressure transducer. The tip of the catheter was threaded up the descending aorta to a position approximately two centimeters below the diaphragm. Central venous pressure was measured, from another saline filled catheter threaded up the superior vena cava, with a Statham P23V transducer. The electrocardiogram was also recorded. The recordings were made on an eight-channel Hewlett Packard recorder, and included the ultrasonic Doppler signal. In addition, the audible Doppler signal was recorded on a high quality magnetic tape recorder for subsequent off-line spectral analysis.

To obtain the ultrasonic Doppler shift signal, one of two ultrasonic probes was used in conjunction with commercial flowmeters (Parks 803 and 806). The first was a simple Doppler probe consisting of a single continuously emitting transmitter alongside a separate receiver, mounted at the end of a nasogastric tube, or polyethylene catheter. The transmitter was set at an angle of 45 degrees to the line of the probe and when in position down the oesophagus was assumed to lie approximately 45 degrees to the line of the aorta, and so to the blood flow. The alternative probe used two transmitters set at 90 degrees to each other, so that the two sonic beams crossed. In vitro testing ${ }^{3}$ had shown that the vector sum of the Doppler shift obtained from the reflection of each sound beam is the true Doppler shift over an angle variation of \pm 20 degrees between the probe assembly and the observed flow. The operating frequency of the ultrasonic beam was $8 \mathrm{MHz}$ and the Doppler shift was obtained by electronically demodulating the back scattered signal detected by the ultrasonic receiver and recording the output from a zero crossing ratemeter on the eight-channel recorder. A full description of the probes used will be the subject of another communication. Calibration of the ultrasonic detecter and amplifiers was achieved by inserting an electronic standard frequency of $2.7 \mathrm{KHz}$ which, with the double probe used, corresponded to the Doppler shift observed when monitoring a flow velocity of 20 centimeters per second in vitro.

In some experiments cross calibration was obtained from the electromagnetic flowmeter placed around the descending aorta, in a position of approximately two centimeters proximal to the position of the ultrasonic probe in the oesophagus. Since the diameter of the aorta was known at this point, and since no major arteries leave the aorta between the two probe positions, the average velocity of the blood flow could be calculated from the electromagnetically observed blood flow rate. Such an independent means of cross calibration was particularly useful when the single ultrasonic probe was used, since the Doppler shift is not only a function of the blood flow but also dependent upon the cosine of the angle between the ultrasonic beam and direction of the blood flow according to the following formula. ${ }^{4}$ 


$$
\begin{aligned}
\Delta \mathrm{f} & =(2 \mathrm{fv} \cos \theta) / \mathrm{c} \\
\text { where } \Delta \mathrm{f} & =\text { change in frequency due to the Doppler effect } \\
\mathrm{f} & =\text { emitting frequency } \\
\mathrm{c} & =\text { speed of conduction of sound in tissues } \\
\theta & =\text { angle between sound beam and particle velocity path } \\
\mathrm{v} & =\text { velocity of the particle reflecting the sound wave }
\end{aligned}
$$

Without this technique of correction a systematic error in the calculation of the exact velocity of blood could develop because of any variation from the 45 degree angle between the probe head and aorta, which had been assumed.

The ultrasonic probe was passed down the oesophagus into the stomach and then withdrawn until clear signals could be obtained. In the dog this corresponded to a position approximately 2 to 3 centimeters above the diaphragm. Its position was verified by radiological screening (Figure 1). In practice there was little difficulty in determining the position of the probe tip. If it was in the stomach the

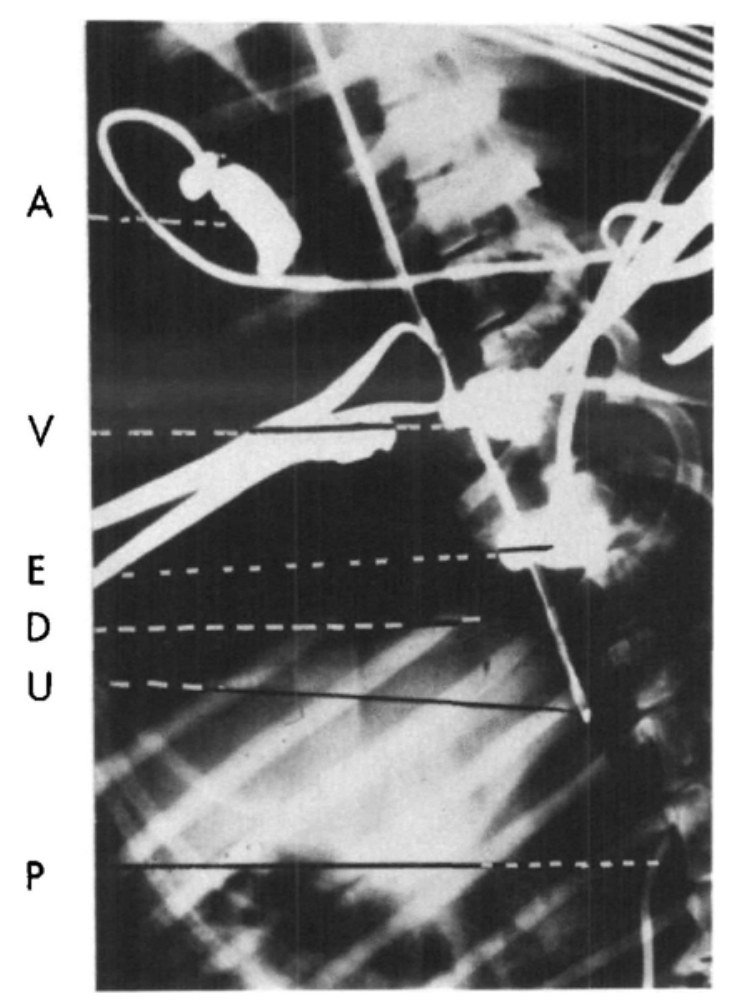

Figune 1. X-ray to show the position of the various sensors.
A. Ascending Aorta electromagnetic flow meter
V. Ventricular Pressure Transducer
E. Electromagnetic flowmeter on descending Aorta
D. Diaphragm
U. Ultrasonic Probe inside oesphagus
P. Pressure catheter for arterial pressure measurement

The central venous pressure cannula can be seen immediately above the ascending aorta electromagnetic flowmeter. 
gastric air bubble provides immediate serious loss of all reflected signal because transmission of ultrasound of this frequency through air is negligibly small. This could be heard with the earphones listening as the sound was being recorded on the tape recorder. There was also a small change in the physical resistance to the passage of the tube as it passed through the cardia.

The stroke volume was obtained by integration of the output of the electromagnetic flowmeter probe that had been placed around the ascending aorta, and multiplying this by the heart rate gave the cardiac output. The mean blood pressure and mean central venous pressure were obtained from integration of their respective waves and dividing these by the time of the cardiac cycle. The total peripheral resistance was then calculated according to the equation ${ }^{5}$

$$
\text { T.P.R. }=\frac{(\text { Mean Arterial Pressure }- \text { Central Venous Pressure }) \times 1332}{\text { Cardiac output per ml per second }}
$$

as expressed as dyne.sec.cm ${ }^{-5}$.

\section{Technique of the EXPERIMENT}

Variations in myocardial contractility, as gauged by the $\mathrm{dP} / \mathrm{dt}$ signal, and in cardiac output and/or blood pressure were produced by the administration of various drugs. The drugs used were calcium chloride, procaine amide, prostigmine, noradrenaline, and the hypotensive agent trimetaphan. Since the object of the drugs was simply to produce a marked change in the haemodynamics the dosage of the drugs was not critically controlled on a dose/weight basis, with the exception of trimetaphan, to which the dog proved to be exquisitely sensitive. The purpose of the drugs was to try to vary the cardiac output and peripheral resistance or blood pressure each independently of the other, as much as possible, in an intact animal; and to produce as many combinations of high, normal, or low cardiac output and high, normal or low blood pressure as could be obtained. Other variations in haemodynamics were produced by acute haemorrhage and reinjection of the blood, and by severe anoxia. In practice it proved impossible to produce the changes in the haemodynamic parameters entirely independent one with respect to another because of the compensatory vascular reflexes that were elicited. However, inspection of the $\mathrm{dP} / \mathrm{dt}$ signal and the blood pressure signal indicated when significant changes had occurred.

\section{RESUlts}

Since the ultrasonic probe measures velocity rather than volume flow, and the pen recorder was assumed to record the mean velocity at any instant - it was necessary to analyse the tape recording of the signal to see if there was a significant spread of velocities at any instant in time during the cardiac cycle. Thus, laminar flow could produce a range of velocities from zero to maximal midstream velocity, whilst turbulent flow could produce a complete spread of velocities of varying and random intensity. The spectral analysis, or sonogram ${ }^{6}$ (Figure 2) showed that most of the Doppler signal intensity was contained within a narrow band around the edge of the sonogram. This suggests that the majority of the flow 


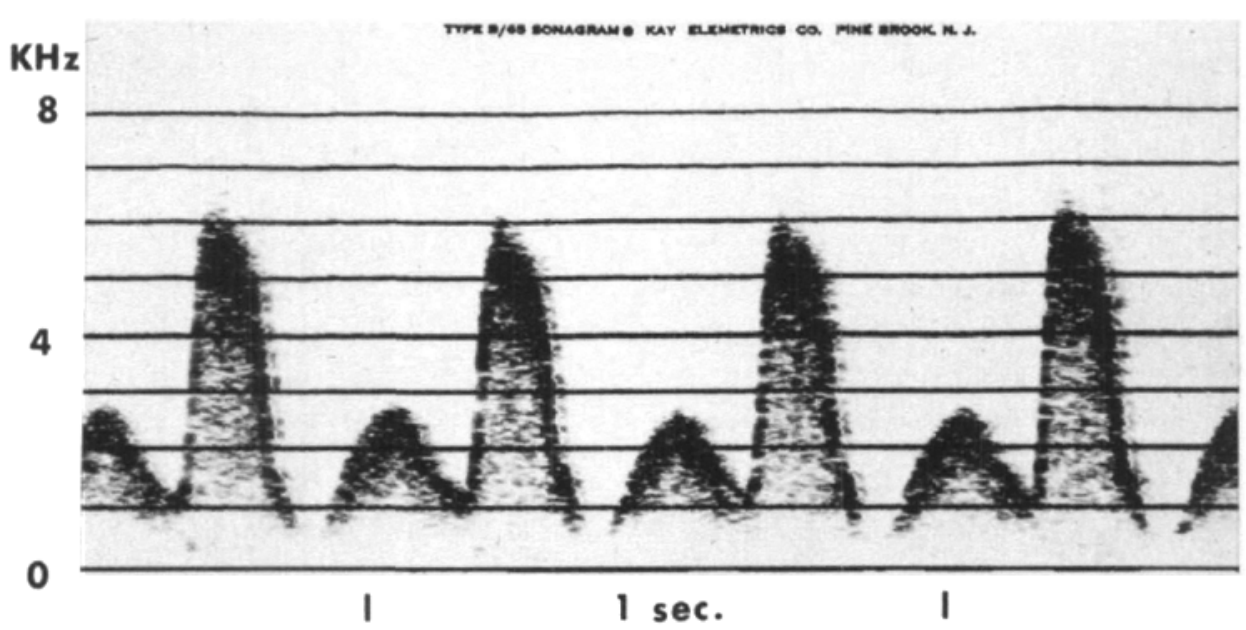

Ficuhe 2. Sonogram obtained from the trans-oesophageal Doppler probe. The trace shows the spectral analysis of the Doppler shifts. Time is on the horizontal axis, and frequency of the Doppler shift on the vertical axis. The signal amplitude or intensity at any given frequency and time is given by the intensity of blackness at that point. The greater the intensity the greater the proportion of the flow at that instant is occurring at that velocity. The bulk of the blackness corresponds to the envelope of the signal and means that the majority of the blood is flowing at the same speed. The effect of laminar flow is negligible.

travelled at the same speed and that disturbance in the range of velocities produced by lamination was negligible. This implies that, as far as the thoracic aorta is concerned, most of the blood moves by bolus flow. This in turn implies that it is reasonable, given a constant cross sectional area, to equate blood velocity with blood flow in large blood vessels.

Cross comparison of the signals obtained from the descending aorta electromagnetic flowmeter probe, which measured blood flow, and the Doppler signal which measured velocity confirmed this. There was good parallelism between the flow record and the velocity record throughout the cardiac cycle (Figure 3 ). This was true only when the probe was low in the oesophagus. When the ultrasonic probe was withdrawn to the level of the arch of the aorta the Doppler signals contained considerable scatter of frequencies which resembled noise. The sonogram confirmed considerable turbulence when the ultrasonic probe was very high in the oesophagus. Comparison of the Doppler record obtained at this level with either of the two electromagnetic flowmeter records also showed relatively poor agreement.

For the measurement of any circulatory parameter, the mean of five consecutive cardiac cycles was taken. The integral of the Doppler wave signals throughout the entire cardiac cycle was taken for each of these five beats. Examination of the Doppler and descending electromagnetic flowmeter signals showed that blood flow and blood velocity were at or near their lowest at the time of appearance of the dicrotic notch on the aortic pressure wave. This point differed significantly in time, from the moment when intraventricular pressure fell to below intra-aortic pressure (Figure 4), that is, it differed from the time of aortic valve closure. The appearance of the dicrotic notch was taken arbitrarily as marking the end of systole as 


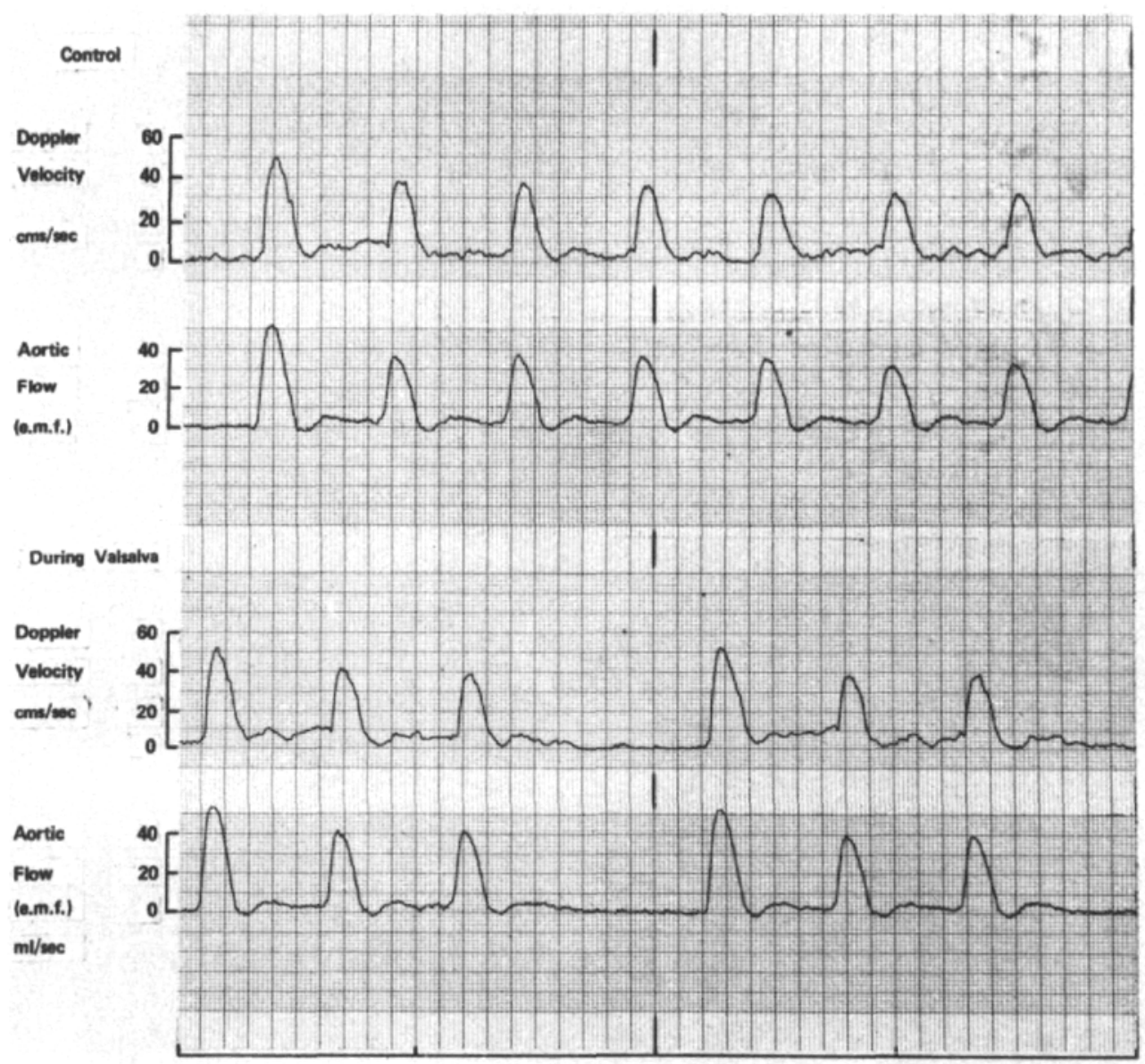

Figure 3. Simultaneous flow and velocity record. The electromagnetic flowmeter probe was around the descending aorta a few centimeters above the level of the trans-oesophageal Doppler probe. It will be seen that there is very close agreement between the observed instantaneous electromagnetic mean flow and velocity. This persists at all ranges of flow during the Cardiac cycle.

far as the descending aorta was concerned and was taken rather than the aortic valve closure point because of the phase delay due to the time taken for the blood flow wave to reach the level of the probes along the descending aorta. It was deduced that any flow of blood detected in the descending aorta following the time of the dicrotic notch could only reflect aortic wall recoil or diastolic flow. The integral of the velocity signal was taken from this point to the beginning of the next flow or velocity wave due to the subsequent ventricular contraction. This figure was then expressed as a percentage of the integral of the total Doppler velocity signal; that is to say the area under the Doppler curve during diastole was taken as a percentage of the total area.

The area under the Doppler curve, or the integral of velocity with time, is proportional to the distance that the red cells are propelled, during the cardiac cycle, against the vascular resistance. This area is exactly analogous to the integral of 


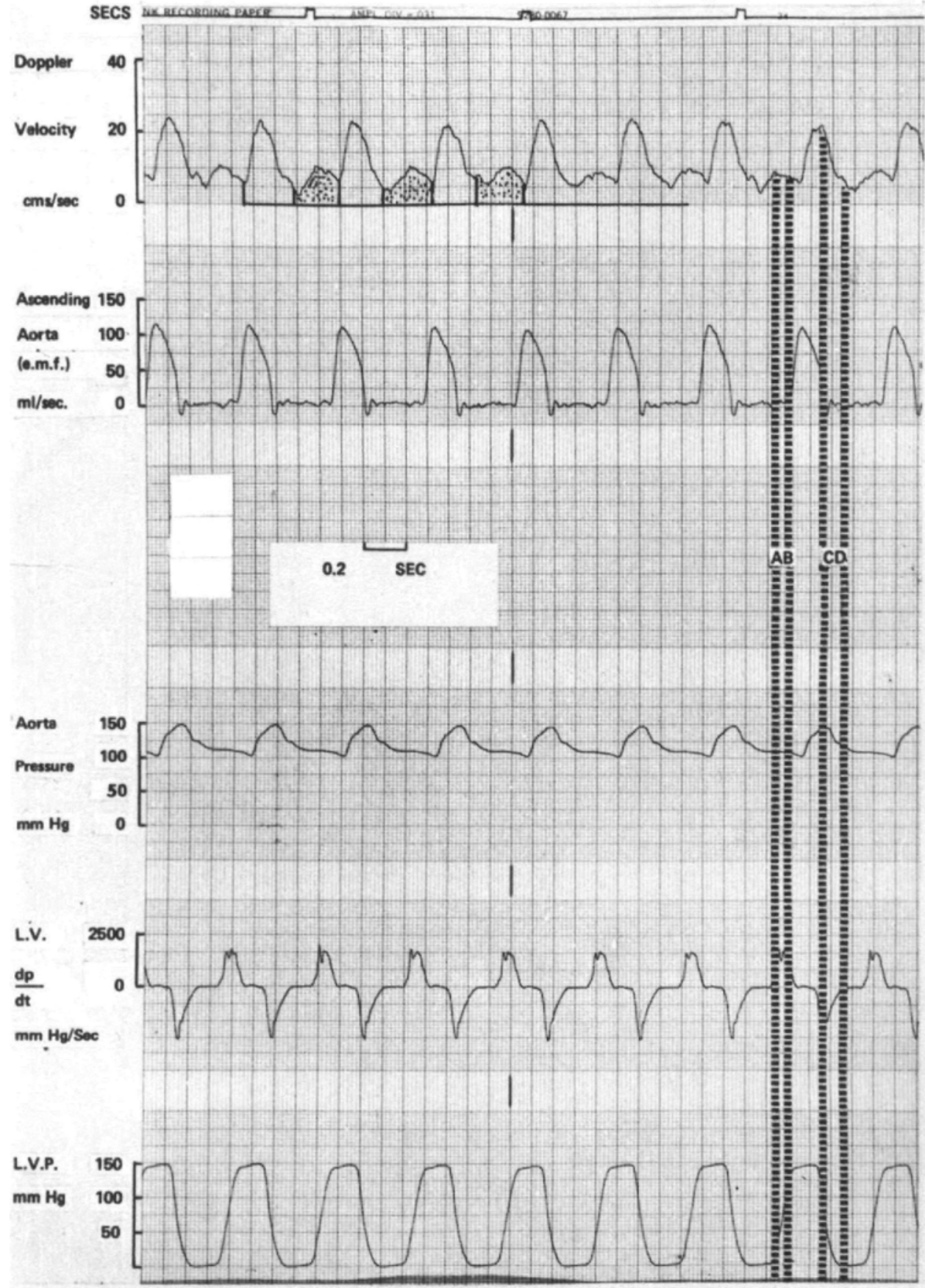

Figure 4. Specimen recording to show the timing of events in relation to the signals. Time marker at the top of the tracing

$A=$ Start of Systole - L.V.P. starts to rise

$\mathrm{B}=$ Opening of Aortic Valves - flow starts in Ascending aorta

$\mathrm{C}=$ Closure of Aortic Valve - L.V.P. falling rapidly, ascending aortic fow ceases

$\mathrm{D}=$ Dicrotic notch - onset of Aortic Diastolic flow wave -0.08 Sec behind the closure of the Aortic valve and after the peak of the reverse flow due to the valve recoil seen by the electromagnetic flow probe

The stippled area of the top tracing is the Diastolic flow wave area, and the ratio between this and the area under the entire cardiac cycle waves is proportional to the total peripheral resistance. 
the flow signal obtained from the electromagnetic flowmeter and time; that is, stroke volume.

Stroke volume, heart rate, mean aortic and central venous pressures were taken for the same five consecutive cardiac cycles and the total peripheral resistance calculated and compared with the ratio of diastolic velocity integral to total velocity integral of the aortic blood, expressed as a percentage.

This was then repeated for a number of episodes when either cardiac output or blood pressure or both were altered. Figure 5 shows the variation in appearance of the diastolic wave when the peripheral resistance is changed, and it will be

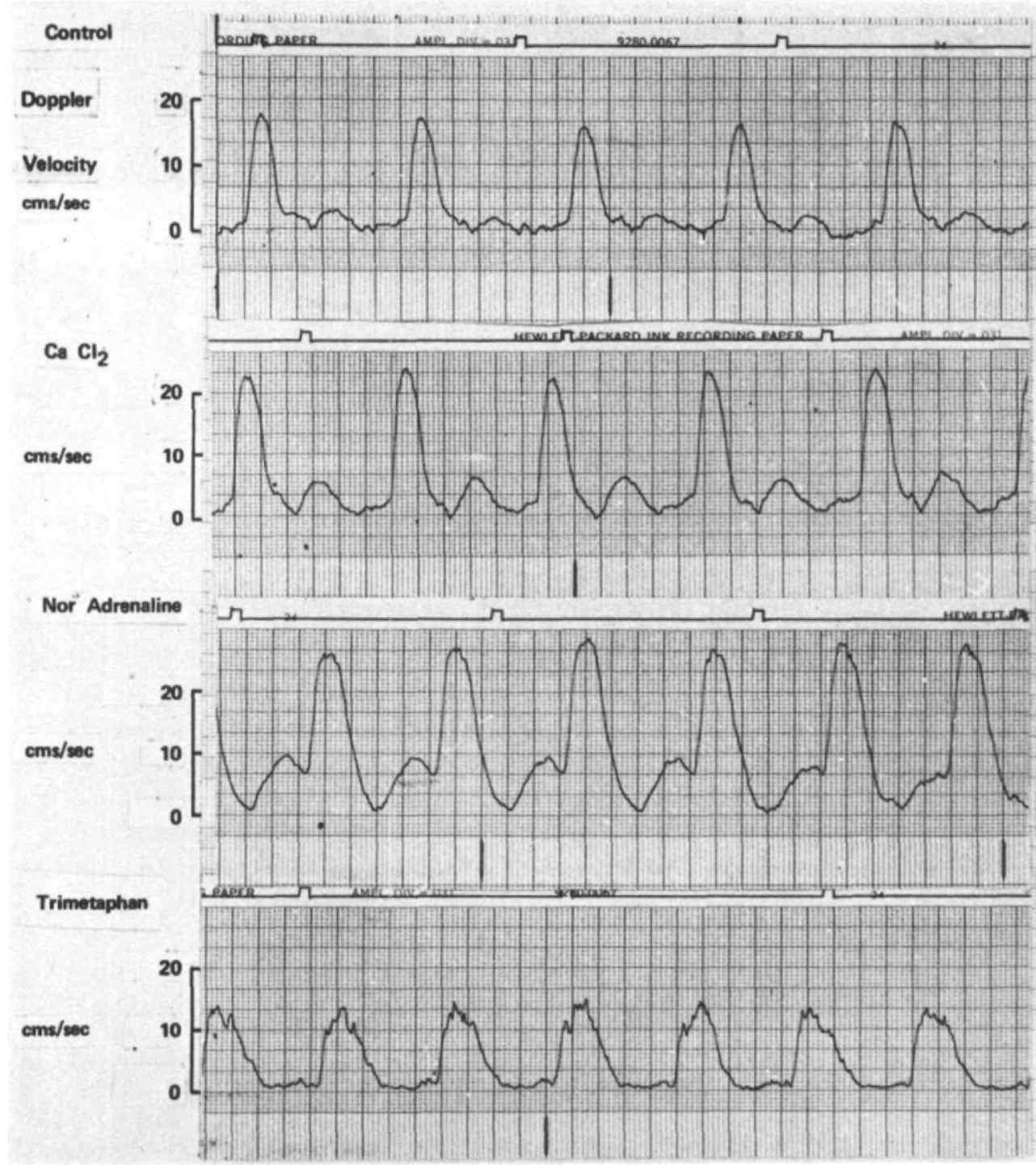

Figure 5. The effects of alterations in total peripheral resistance on the appearance and size of the aortic diastolic wave. The proportion of the total area under the curves during diastole is significantly increased when a vaso-constrictor drug is used, and decreased when a vaso-dilator drug is used. 
seen that alterations in peripheral resistance will not only change the shape of the diastolic wave of the Doppler signal but also the area contained underneath the wave.

For each dog there was an average of nine paired readings (range 3-15) between total peripheral resistance and percentage diastolic to total velocity integral ratios. The ranges in total peripheral resistance varied from one third of the control value for total peripheral resistance produced by trimethaphan, up to a five-fold increase over this value. Table I gives the range of the changes in this total peripheral resistance in each dog.

\section{TABLE I}

CORRELATION COEFFICIENTS AND PROBABILITIES RESULTING WHEN TOTAL PERIPHERAL RESISTANCE IS COMPARED AGIAINST THE PERCENTAGE BLOOD FLOW OBSERVED IN THE DESCENDING AORTA DURING DIASTOLE

\begin{tabular}{|c|c|c|c|c|c|c|}
\hline \multirow[b]{2}{*}{ Dog } & \multirow{2}{*}{$\begin{array}{c}\text { Range of } \\
\text { T.P.R. as } \\
\% \text { of control }\end{array}$} & \multirow{2}{*}{$\begin{array}{c}\text { Range of } \\
\text { Diastolic area/total } \\
\text { area ratios } \%\end{array}$} & \multirow{2}{*}{$\begin{array}{l}\text { Correlation } \\
\text { Coefficient }\end{array}$} & \multicolumn{3}{|c|}{ Student } \\
\hline & & & & $\mathrm{N}$ & $\mathrm{t}$ & $\mathrm{P}$ \\
\hline $\mathrm{E} 1$ & $67-183$ & $14.2-40.1$ & 0.949 & 7 & 6.79 & 0.005 \\
\hline $\mathrm{E} 2$ & $75-272$ & $12.8-59$ & 0.8713 & 10 & 5.021 & 0.0025 \\
\hline E3 & $39-355$ & $10-23.4$ & 0.739 & 10 & 3.092 & 0.01 \\
\hline $\mathrm{E} 4$ & $82-126$ & $18.6-30.7$ & 0.9639 & 3 & 3.6199 & $01-0.05$ \\
\hline $\bar{E}$ i) & $91-483$ & $20-49.3$ & 0.9999 & 3 & 70.1 & 0.0025 \\
\hline E7 & $51-372$ & $9.2-20.6$ & 0.7587 & 11 & 3.6938 & 0.0025 \\
\hline E8 & $46-172$ & $11.9-24.4$ & 0.7716 & 6 & 2.426 & 0.025 \\
\hline $\mathrm{E} 10$ & $50-238$ & $12.8-26.9$ & 0.7412 & 13 & 3.5516 & 0.0025 \\
\hline E11 & $32-27 i$ & $15-48$ & 0.876 & 15 & 6.55 & 0.0005 \\
\hline
\end{tabular}

When the ratio of diastolic to total velocity (percentage) was plotted against total peripheral resistance the graph was linear (Figure 6). Simple linear regression analysis between total peripheral resistance and percentage diastolic flow gave statistically highly significant correlations for each dog, with correlation coefficients varying from 0.739 to 0.999 ( Table I).

Peak velocity was also compared with total peripheral resistance and in five out of nine dogs there was a statistically significant negative correlation (Table II). That is to say, the higher the peripheral resistance the lower the peak velocity achieved during systole. The correlation only held if the heart was not too depressed, that is, if the $\mathrm{dP} / \mathrm{dt}$ was not too small. The four dogs in which peak velocity was not correlated with peripheral resistance in a statistically significant fashion had an extremely wide scatter of results. Notwithstanding, the sign test on the findings that eight of the nine regression coefficients were negative is statistically significant at a probability of 0.0176 .

\section{Discussion}

The purpose of the investigation was to determine if the total peripheral resistance and diastolic blood flow, as observed in the descending aorta, were related. This was confirmed over a wide range of values when total peripheral resistance was changed by a variety of means such as drugs, haemorrhage or anoxia. The greatest increase in the total peripheral resistance was seen in the 
TABLE II

REgRESSION EQUATIONS RESULTING WHEN V.MAX IS EXPRESSED AS A LINEAR FUNCTION OF ThE TOTAL PERIPHERAL RESISTANCE

\begin{tabular}{rlrccc}
\hline \hline & & & & \multicolumn{2}{c}{ Student } \\
\cline { 3 - 6 } Dog & Regression Equations for V.Max & $\mathrm{N}$ & $\mathrm{r}$ & $\mathrm{t}$ & $\mathrm{P}$ \\
\hline 1 & $284-4.5( \pm 184 \%)$ T.P.R. & 7 & -0.237 & -0.541 & 0.3 \\
2 & $70.49-3.47( \pm 15 \%)$ T.P.R. & 10 & -0.9198 & -6.63 & $0.000 \overline{1}$ \\
3 & $26+0.23( \pm 215 \%)$ T.P.R. & 10 & 0.152 & 0.463 & 0.35 \\
4 & $64-5.19( \pm 20.5 \%)$ T.P.R. & 3 & -0.9796 & -4.8747 & 0.05 \\
5 & $16.43-2.2( \pm 21.2)$ T.P.R. & 3 & -0.9782 & -4.7093 & 0.05 \\
7 & $25.14-0.867( \pm 35.7)$ T.P.R. & 11 & -0.68211 & -2.801 & 0.01 \\
8 & $34.14-0.68( \pm 93.9)$ T.P.R. & 6 & -0.4699 & -1.6046 & 0.2 \\
10 & $25.53-2.74( \pm 92.8)$ T.P.R. & 13 & -0.308 & -1.0771 & 0.2 \\
11 & $30-1.08( \pm 33.19)$ T.P.R. & 15 & -0.64 & -3.0126 & $0.00 i$ \\
\hline
\end{tabular}

The probability of having 8 out of 9 equations showing an inverse association between the two is less than 0.01, not withstanding the fact that some of these equations were in themselves not significant at the $5 \%$ level. Figures in parenthesis are Standard Deviations of the Mean of the regression coefficients, expressed as a percentage of those coefficients. It will be scen that the equations in which this was large had the statistically not significant associations i.e., the scatter in these particular equations was too widc.

terminal phases of severe anoxia, when cardiac output and blood pressure were both very low; but the vascular resistance was so high that the fall in cardiac output was proportionately very much greater than the fall in blood pressure. Despite the very low velocities achieved in the aorta under these particular conditions the relationship between diastolic and total velocity flow was still maintained although the definition of the signal indicating the beginning of diastole was very much less clear.

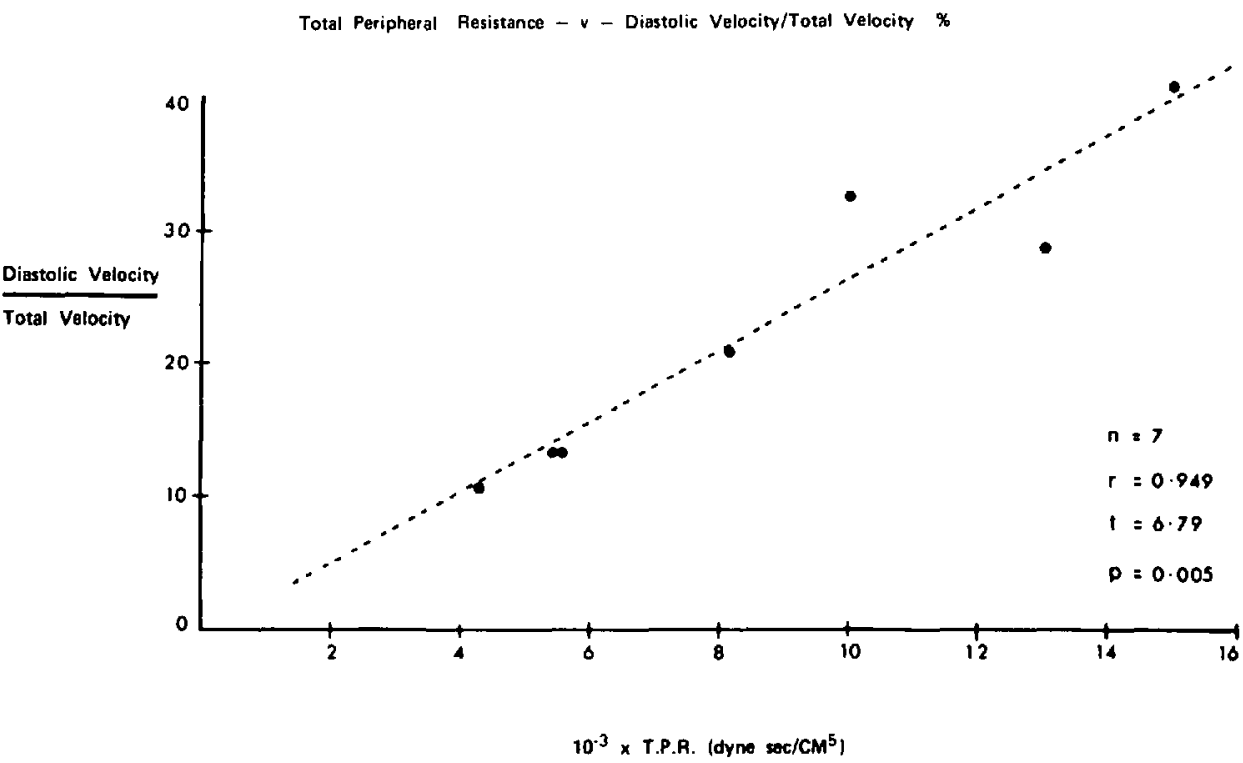

Figure 6. The linear regression resulting when the ratio of diastolic area to total curve area, of the areas under the velocity tracing recorded from the ascending aorta, is plotted against the total peripheral resistance. 
The advantages of this ultrasonic system is that the Doppler shift signal can be displayed on a simple oscilloscope, such as one used for monitoring the electrocardiogram. Simple inspection of the diastolic component of the wave readily shows whether this diastolic component is assuming a greater or lesser proportion of the total wave area. This would appear to be its main advantage. Because one is looking at the ratio between the diastolic and the total wave component, calibration and angular alignment of the probe to the aorta becomes unimportant. This system allows beat to beat inspection of the peripheral resistance in patients in the operating room.

The position of the tip of the ultrasonic probe in the oesophagus is of some importance. If the probe tip is near the arch of the aorta considerable disturbance of the signal may result from the turbulence of the blood flow at this point. Further down the oesophagus, once bolus flow is re-established, the greater is the proportion of flow which occurs in diastole. This is because the diastolic flow is generated by the distension of the aorta during systole and the higher the peripheral resistance the more the aorta is distended the greater is the recoil that gives diastolic flow. If the probe tip is relatively high in the aorta there is less volume of aorta between it and the heart to store the blood that will subsequently be used for diastolic flow, and therefore the proportion of diastolic flow will change with the position of the probe vis-à-vis the length of the aorta. In practice this means that once a reference point is chosen the probe tip must remain constant in position.

We have arbitrarily chosen 2 to $2.5 \mathrm{~cm}$ above the diaphragm as representing the best compromise obtainable when passing the probe down the oesophagus. In this position the maximum volume of aorta is between the probe head and the aortic valve, and yet the tip is sufficiently high above the diaphragm to prevent loss of signal from the gastric air bubble.

The general hypothesis that the observed diastolic flow is due to the peripheral resistance causing aortic distension would seem to be confirmed by the good negative correlation between peak velocity and the total peripheral resistance. This is not surprising when one considers what happens when the total peripheral resistance is raised. The energy then required to give blood the same velocity at peak flow as when the resistance is normal would be significantly higher because the pressure required would be considerably higher. Thus quadrupling the peripheral resistance would quadruple the pressure required to produce the same flow and velocity. For a given resistance, reducing the velocity means that the pressure generated does not have to be so much. Since kinetic energy is proportional to the square of velocity, any coupling system (e.g., the distensible aorta) that allows the instantaneous velocity to be reduced without altering the average flow saves the heart much work. Thus the elastic properties of the aorta appear to act as a buffer to minimise the amount of energy the heart must generate at any instant in time.

Increasing the diameter of the aorta allows the same fow at a reduced velocity. An increase of five per cent in the radius of the aorta causes the area to increase by approximately 10 per cent and, for the same flow, velocity is reduced by 10 per cent. This in turn means a reduction of approximately 20 per cent in energy 
requirements. O'Rourke ${ }^{7}$ has in fact deduced that the pulsatile energy losses would be 50 times greater than they are if the heart pumped directly into the peripheral arterioles. Yet this is where the greatest proportion of the peripheral resistance occurs. Storing the blood in the upper aorta for subsequent discharge during diastole is another way of saving energy. This implies that any loss of elastic tissue in the aorta would lead to a very marked increase in the work of the heart and high peak systolic pressures and velocities. This may well be the reason why patients with atheromatous aortas go into heart failure so easily and also why their systolic pressure and pulse pressures are so high. They have lost their diastolic pumps and the means of spreading the total work into the diastolic time. O'Rourke $^{8}$ has also noted this. In contradistinction the observation of a low peripheral resistance as gauged by a low diastolic flow seen with the Doppler flowmeter, plus a low peak velocity would imply significant myocardial depression in that the heart was unable to increase its energy output despite a lowered resistance load.

\section{SUMMARY}

Trans-oesophageal ultrasonic monitoring of aortic blood flow was found to offer a system allowing beat to beat observation of the total peripheral resistance, without the need of a very sophisticated calibration technique. Experimental evidence from dogs indicates a very good correlation between the total peripheral resistance and the proportion of the stroke volume flowing down the aorta during diastole. There was also a very good negative correlation between the maximum systolic velocity and the total peripheral resistance. This combination would suggest that the elastic properties of the proximal aorta play an important role in reducing the instantaneous work load on the myocardium.

\section{RÉSUMÉ}

Une étude chez les chiens a démontré que l'emploi d'une électrode ultrasonique de type Doppler, contenue à l'intérieur d'un tube naso-gastrique ordinaire et placée dans l'œsophage à la hauteur du diaphragme, a permis de mesurer la vélocité du débit sanguin dans l'aorte descendante. Le sang circule comme un bolus et il existe un parallélisme étroit entre les données obtenues à l'aide du Doppler et celles d'un débitmètre électro-magnétique placé autour de l'aorte descendante; et ceci, en dépit du fait que l'un des appareils mesure un débit, et l'autre une vélocité. La surface sous-jacente à la portion diastolique du tracé du Doppler, lorsqu'exprimée en pourcentage de la surface totale, varie de façon linéaire avec les changements de la résistance périphérique, à condition que le myocarde ne soit pas trop déprimé. Le débit diastolique est causé par la distension systolique de la partie supérieure de l'aorte qui se rétracte durant la diastole. Cette distensibilité a sur le cœur un rôle important d'épargne d'énergie, en permettant d'une part une diminution de la vélocité maximale et d'autre part, l'extension de la période de travail utile durant la diastole.

Ainsi le cœur et la circulation systémique sont dissociés et le débit est en partie transformé du mode cyclique à sommet élevé à un mode plus continu de moindre intensité. 


\section{REFERENCES}

1. Hodson, C.J. \& Duck, F.A. Blood Flow monitoring in deeply situated arteries. J. Invest. Radiol. 8: 160 (1973).

2. Gersch, B.J., Hahn, C.E.W., \& Prys-Roberts, C. Physical criteria for the measurement of left ventricular pressure and its first derivative. Cardiovasc. Res. 5: 32 (1971).

3. Duck, F.A. \& Hodson, C.J. A practical method of eliminating the angular dependence of Doppler flow measurements. Proc. 2nd World Congress on Ultrasonic in Medicine. Excerpta Medica, Internat. Conf. Series 277: 15 (1973).

4. Side, C.O. \& GosLing, R.G. Non-surgical assessment of cardiac function. Nature 232: 335 (1971).

5. Mahshall, H.W., Helmholtz, M.F., \& Wood, E.H. Physiological consequences of congenital heart disease. In handbook of Physiology Section 2. Circulation p. 428. Editor Hamilton, W.F. Publishers, American Physiological Society.

6. Kaneku, Z., Shiraishi, J., Omizo, H., MotimiYa, M., Izumi, T., \& Oxumara, T. Analysing blood flow with a sonagraph. Ultrasonics 4: 22 (1966).

7. O'Rourke, M.F. Steady and pulsatile energy losses in the systemic circulation under nomal conditions and simulated disease. Cardiovasc. Res. 1: 313 (1967).

8. O'Rourke, M.F. Arterial haemodynamics in hypertension. Circulat. Res. 18: 126 (1970). 